\title{
El abuso de conciencia \\ Hacia una definición que permita su tipificación penal canónica
}

\author{
CRISTIÁN BORGOÑO* \\ Pontificia Universidad Católica de Chile (Chile) \\ cborgono@uc.cl \\ CRISTIÁN HODGE** \\ Universidad San Sebastián (Chile) \\ cristian.hodge@uss.cl
}

\begin{abstract}
Resumen
Este estudio tiene como objetivo perfilar el concepto de abuso de conciencia en vistas a su tipificación en el derecho canónico. Se comienza describiendo la reflexión postconciliar sobre la manipulación de conciencia desde una perspectiva teológico-moral, que anticipa el concepto actual de abuso de conciencia. El centro del artículo es el esclarecimiento del concepto de abuso de conciencia y de su gravedad. Este abuso se da en el contexto de relaciones de cuidado, donde se traspasan los límites de la mediación eclesial que corresponde a dicha relación: el abuso de conciencia implica apropiarse indebidamente de la autoridad de Dios. El presente estudio continúa la línea de investigaciones precedentes para perfilar con mayor nitidez el abuso de conciencia propiamente tal en el contexto católico. Es un paso indispensable para la necesaria justicia y reparación para las víctimas de este grave delito. Palabras clave: abuso de conciencia, abuso espiritual, manipulación de conciencia, relación de cuidado, teología moral, derecho canónico.
\end{abstract}

\section{Abuse of conscience \\ Towards a definition that allows its canonical typification}

\begin{abstract}
This article offers a systematic characterization of abuse of conscience in order to its typification as a canonical crime. We begin exploring the study of conscience manipulation in moral theology after $V$ atican II as an important background for the understanding of abuse of conscience in more recent studies. The core statement of this study is the definition of abuse of conscience and its gravity. This kind of abuse is set within care relationships, where the abuser steps over the limits of his ecclesial mediation: he appropriates bimself of God's own authority. This study builds on this literature to understand abuse of conscience as a specific type of spiritual abuse in catholic settings. We understand this is absolutely necessary for justice and reparation towards victims.
\end{abstract}

Key words: abuse of conscience, spiritual abuse, conscience manipulation, care relationship, moral theology, canon law.

* Doctor en Bioética por el Ateneo Pontificio Regina Apostolorum. Profesor y Secretario Académico de la Facultad de Teología de la PUC.

** Doctor en Teología por la Pontificia Universidad Católica de Chile. Académico y Director del Programa de Doctorado en Filosofía de la Facultad de Humanidades y Ciencias Sociales de la Universidad San Sebastián (Chile). 


\section{INTRODUCCIÓN}

Con mucha frecuencia, el abuso de conciencia aparece conformando una tríada con el abuso de poder y el abuso sexual (Francisco, 2018) ${ }^{1}$. Sin embargo, sólo en el último tiempo el abuso de conciencia está adquiriendo una identidad propia, como un tipo de abuso espiritual. El mismo Papa Francisco reconoce el problema:

En este tiempo tenemos una gran tentación en la Iglesia, que es el «acoso» espiritual: manipular las conciencias; un lavado de cerebro teologal, que al final te lleva a un encuentro con Cristo puramente nominal, no con la Persona de Cristo Vivo. En el encuentro de una persona con Cristo, entran Cristo y la persona. No lo que quiere el ingeniero espiritual que busca manipular. (Francisco, 2013)

Mientras pocos niegan la existencia de este tipo de abuso, probablemente no se le atribuye una gravedad igual a la del abuso sexual y quizás por eso, como sostiene Doris Wagner, es un tema que requiere ser mayormente visibilizado y afrontado (Wagner, 2019)2.

En un artículo ya publicado en la revista de nuestra Arquidiócesis (Borgoño \& Hodge, 2020) hemos analizado preliminarmente el concepto del abuso de conciencia. Las reflexiones que siguen buscan profundizar en este tema, poniendo mayormente en relevancia sus aspectos teológicos y precisando ulteriormente la definición del abuso de conciencia a partir de literatura más reciente.

En una encuesta aplicada a más de 1.500 personas, Oakley, Kinmond y Humphreys descubrieron que cerca de un 75\% de las personas habían experimentado alguna forma de abuso espiritual (Oakley, Kinmond \& Humphreys, 2018: 144) $)^{3}$. Al igual que el abuso sexual no es un problema nuevo, como señalaban Johnson y Van Vonderen (1991), hay evidencia de formas similares de abuso espiritual desde hace siglos, como nos lo recuerdan las denuncias de los profetas o las diatribas de Jesús con los fariseos (Jer 5, 26-31; Jer 6, 13-14; el capítulo 23 del Evangelio de

$1 \quad$ El Papa repite tres veces la referencia a esa tríada.

2 En esta publicación, además de dar su testimonio, la autora explora con profundidad el problema, a pesar de que, a nuestro parecer, no distingue adecuadamente el abuso de poder del abuso de conciencia. Esperamos una pronta traducción castellana de esta obra, por ahora disponible sólo en alemán.

3 El número puede impresionar a primera vista por su magnitud, sin embargo, hay que tener en cuenta que puede haber un sesgo de autoselección, dado que la muestra fue obtenida por adscripción voluntaria. Debe notarse, además, que poco más del 1\% de los que responden son católicos. Más allá de este dato, nos parece que el abuso espiritual tiene una prevalencia digna de consideración. 
Mateo). Sin embargo, no cabe duda de que el desarrollo reciente de la teología de la conciencia, después del Concilio Vaticano II, ofrece poderosas herramientas para comprenderlo con mayor precisión y cabalidad, de modo de poder abordarlo con más detalle y profundidad.

El término abuso espiritual emerge inicialmente en el mundo protestante a inicios de los 90 y en la literatura anglosajona en torno al counselling psicológico (Henzel, 1997). En el ámbito católico el problema fue desplazado por la gran crisis de los abusos sexuales, ampliamente conocida. Sin embargo, como veremos más abajo, la manipulación de conciencia era un problema que ya ha había atraído la atención de los teólogos católicos.

En la literatura, el concepto de abuso de conciencia suele encuadrarse en el marco del así llamado abuso espiritual, del cual muchas veces no se distingue. El abuso espiritual es un concepto que ya ha sido explorado con cierta amplitud desde la psicología, pero suele utilizarse más como una categoría que engloba formas distintas de abuso en un contexto religioso (Gubi \& Jacobs, 2009; Johnson \& Van Vonderen, 1991; Booth, 1992; Enroth, 1993) que como un concepto preciso que se refiera a formas particulares de relación, en un ambiente religioso, que implican actuar sobre la conciencia de las personas ${ }^{4}$. Tratando de aproximarse a la realidad del abuso espiritual se puede decir que se da cuando hay un "uso indebido de los medios espirituales de crecimiento personal por parte de las personas que proporcionan ayuda espiritual, como, por ejemplo, los pastores, los profesores o los líderes de comunidades religiosas" (Wang, 2006: 26). Se utiliza la palabra abuso espiritual, también como una forma de no quedar confinados en el ámbito de la religión organizada, como sugiere Demaris Wehr (2000).

En definitiva, como podemos ver, el concepto de abuso espiritual es muy amplio y de contornos imprecisos. Sin embargo, nos parece claro que el concepto de abuso de conciencia se encuadra dentro del marco del abuso espiritual, a pesar de que no se lo distingue explícitamente en las publicaciones más pioneras sobre el tema, la mayoría de ellas en el marco del cristianismo no-católico. Esto no debe extrañar puesto, que distinciones como las de fuero interno y fuero externo, que son habituales en un contexto religioso católico, son desconocidas y poco tematizadas en

$4 \quad$ La Iglesia reconoce que hay ciertas relaciones donde de suyo hay una manifestación de la conciencia, como la confesión o el acompañamiento espiritual. En otras formas de relación asimétrica relacionadas con el gobierno o conducción de comunidades religiosas, se asume que no existe un deber de manifestar la conciencia. Durante el último tiempo, la Iglesia ha intentado que estas dos relaciones no coincidan, sino que se mantengan separadas. Un ejemplo de esto son los cánones 239 y 240 del Código de Derecho Canónico. 
el ámbito psicológico clínico y en otras confesiones. En efecto, si ya al interior de la Iglesia Católica estas distinciones no son demasiado claras (Rodríguez Luño, 2007), es de esperar que fuera de ella lo sean todavía menos. Sin embargo, tanto la teología como el derecho canónico tienen herramientas conceptuales suficientes para circunscribir con precisión el abuso de conciencia y distinguirlo adecuadamente del abuso de poder. Por eso mismo, nos parece necesaria una reflexión más profunda y sistemática que permita transformar, eventualmente, el abuso de conciencia en un delito canónico que pueda ser efectivamente sancionado ${ }^{5}$. Desgraciadamente, la recién publicada reforma del derecho canónico penal (Francisco, 2021), no incluye una tipificación del abuso de conciencia, de hecho, ni siquiera lo menciona.

Para lograr una adecuada descripción y delimitación del abuso de conciencia, buscaremos primero revisar cómo se ha elaborado el concepto de intervención indebida en la conciencia ajena, a partir del análisis del concepto de manipulación de conciencia después del Concilio, que nos parece un precursor del término actual de abuso de conciencia ${ }^{6}$. En un segundo momento procuraremos proponer una definición de abuso de conciencia que tenga la suficiente claridad y precisión para servir de base a la tipificación del delito de abuso de conciencia, al menos en sus formas más graves. Finalmente, examinaremos los motivos por los que nos parece que el abuso de conciencia debe ser considerado un delito y no meramente una desviación o imperfección de la relación de cuidado espiritual en la que se enmarca.

5 En 2018, la Iglesia de Inglaterra sancionó a un vicario parroquial por abuso espiritual en contra de un menor de 15 años. https://www.theguardian.com/world/2018/jan/08/church-of-england-finds-vicarguilty-of-spiritual-abuse-of-15-year-old-boy . No son raros los casos en que hay tanto abuso sexual como abuso de conciencia, sin embargo, es muy difícil decir qué penas corresponden al abuso de conciencia y cuáles al abuso sexual. A título de ejemplo, pueden considerarse estos casos, de amplia cobertura mediática. https://www.t13.cl/noticia/nacional/iglesia-confirma-religioso-abuso-sexualmente-

dos-adultos-san-felipe; https://www.biobiochile.cl/noticias/nacional/region-de-laaraucania/2020/01/24/quitan-estado-clerical-a-sacerdote-valdebenito-tras-confirmarseabusos-sexual-a-menores.shtml.

6 Incluso en algunos documentos recientes se sigue utilizando este término, por ejemplo, en el documento "Prevención de abusos sexuales a niños, niñas, adolescentes y adultos vulnerables en obras y ministerios de la Compañía de Jesús" de mayo de 2021. Disponible en: https://jesuitas.cl/cpr/ 


\section{LA MANIPULACIÓN DE CONCIENCIA}

La intromisión indebida en la conciencia ajena no es algo exclusivo de nuestros tiempos, al desarrollarse una teología de la conciencia, sobre todo después del Concilio Vaticano II -que busca ir más allá de su acepción exclusivamente moral-, han emergido conceptos como la manipulación de conciencia, que puede considerarse como una antigua forma de pensar lo que hoy entendemos como abuso de conciencia.

Conviene distinguir manipulación de conciencia de formación de la conciencia. Cuando la teología moral trata la formación de la conciencia (Melina, Noriega \& Pérez Soba, 2007: 843-846) lo hace desde una aproximación distinta de cómo lo entiende la filosofía (Chávez, 2021: 121 123), la psicología y otras ciencias (Damasio, 2020: 279). La formación de la conciencia es un deber ético muy importante. Debe ser personalizada, ya que hay que respetar el que cada persona permanezca dueña de sí misma. El riesgo y el límite para el formador o acompañante es educar la conciencia y, al mismo tiempo, respetar al sujeto para que camine de la heteronomía a la autonomía de la conciencia en su relación con Dios.

Al tratar sobre la formación de la conciencia, Sabatino Majorano (1994: 123-145) afirma que los responsables son la familia, la escuela y la comunidad cristiana. Si la educación ética en el pasado estaba más centrada en los preceptos morales, hoy se fortalece la convicción y la asimilación personal de los contenidos éticos transmitidos.

La interdependencia entre la verdad y la conciencia, subrayada por la Declaración conciliar Dignitatis humanae (Concilio Vaticano II, 1965c) no permite hablar de la formación de la conciencia sin una sincera tensión en la búsqueda de la verdad. Por otra parte, para el creyente, la palabra de Dios, la liturgia y el magisterio son una guía en el camino personal y comunitario de la formación de la conciencia. Melina, Noriega y Pérez Soba hablan de la forma cristiana de la conciencia moral, afirmando que "es «en Cristo» donde la persona alcanza la verdad de su ser y la conciencia moral, su forma definitiva" (2007: 840). Estos autores continúan explicando que "la conciencia cristiana es la participación que se nos da en la conciencia filial de Cristo, que en el Espíritu está ante el Padre, para cumplir la voluntad de salvación". Sobre la necesidad de leyes escritas y autoridades exteriores sostienen que "la comprensión teológica de la conciencia cristiana, entre un ya (primicia del Espíritu) y un todavía no (necesidad de una ley escrita), permite superar la alternativa entre autonomía y heteronomía" (2007: 842). Es en la reflexión sobre la conciencia moral donde las distintas escuelas teológico-morales entienden de diverso modo la autonomía y la heteronomía moral. Para estos autores "contra toda pretensión autonomista, en la conciencia filial del cristiano hay una alteridad 
que permanece y que puede expresarse en una obediencia que acepta sin entender" (2007: 842). En definitiva, la formación de la conciencia requiere siempre una alteridad que impida que la persona caiga en una suerte de solipsismo moral, donde podría incluso perderse la referencia al mismo Dios, propia de la conciencia cristiana.

L. Oakley y J. Humphreys (2021) al definir y explicar el abuso espiritual usan principalmente los conceptos de coerción y control en contexto religioso. También se asocian frecuentemente estos conceptos en ámbito católico (Pacheco Romero, 2019). No obstante, Oakley y Humphreys (2021: 61) recurren al concepto de manipulación y lo utilizan en primer lugar al explicitar qué se entiende por abuso espiritual tanto en la definición que entregan el capítulo 2 de su libro "Escapando del laberinto del abuso espiritual" como en el análisis de las características del abuso espiritual del capítulo 3 (2021: 96). La manipulación es un concepto transversalmente usado por estos autores cuando describen las características del abuso espiritual.

Por ejemplo, en el capítulo 4, al analizar el impacto del abuso espiritual, L. Oakley y J. Humphreys escriben: "En muchas de las definiciones de abuso espiritual que la gente proporcionó, la manipulación de estos factores fue central, con «personas que usan la fe, Dios o las creencias [sic] para manipular, controlar y dañar a otros»" (2021: 110. La cursiva es nuestra).

Por otra parte, los mismos autores, citando un anterior estudio del año 2017, afirman que "esto pasa cuando un líder o los líderes principales de una iglesia operan con su propia autoridad mientras abusan y manipulan a la comunidad cristiana y empiezan a tomar el lugar de Dios en sus vidas" (2021: 36. La cursiva es nuestra). Por tanto, parece relativamente asentado que la manipulación es una característica del abuso espiritual. En la parte dedicada a entregar pistas para la creación de culturas más seguras y sanas, estos autores advierten que "es crucial tomar conciencia sobre las Escrituras y los textos sagrados para que las personas sepan reconocer cuándo se están utilizando para manipular' (Oakley \& Humphreys, 2021: 171. La cursiva es nuestra).

\subsection{Una reflexión teológica sobre la manipulación}

K. Rahner (1971) ha escrito un iluminador texto que estudia la libertad y la manipulación en la sociedad y en la Iglesia ${ }^{7}$. Al inicio de su reflexión afirma una verdad antropológica fundamental: "El hombre, como

Esta reflexión rahneriana ha seguido siendo referencia en estudios posteriores sobre el amplio tema de la manipulación humana; por ejemplo, Higuera Udías (1985). 
ser teológico, en el problema de su salvación, o es un sujeto de libertad o no es nada" (Rahner, 1971: 22) ${ }^{8}$. De ahí que, en un análisis sobre el abuso de conciencia, situado en un contexto religioso, y bajo la óptica de la manipulación, el intervenir directamente en la libertad de una persona y en temas referidos a su salvación es sumamente grave. Por otra parte, el teólogo alemán es consciente que "el hombre es una unidad, nunca adecuadamente refleja y nunca propiamente estática, compuesta, por un lado, de libertad y de un ámbito de libertad y, por otro lado, de manipulabilidad (también en su dimensión sociológica)" (1971: 32). Este concepto de manipulabilidad del ser humano es una manifestación de su vulnerabilidad y permite comprender un aspecto de la condición humana que hace posible el abuso de conciencia, cuando no se toman las precauciones personales y comunitarias para prevenirlo.

Por otra parte, K. Rahner distingue entre una manipulación moralmente neutra de una manipulación pecaminosa. La primera manipulación ocurre cuando la libertad de las personas influye o afecta la libertad de otros, esto es parte de la vida social y se da en la historia de la humanidad: "Una acción libre que, intencionada o inintencionadamente, trasforma el ámbito de libertad de otro, con anterioridad al consentimiento de éste, sí puede denominarse, en un sentido metafísico-antropológico y teológico, «violencia» o «manipulación»" (Rahner, 1971: 25). La segunda manipulación da cuenta de la condición concupiscente del ser humano: "aquella alteración libre del ámbito de libertad de otro individuo, que es previa al consentimiento de éste, y que, o bien siempre o bien en una determinada situación, es inmoral y por tanto se dirige contra la libertad de éste otro" (Rahner, 1971: 26). Esto se da a nivel estructural y a nivel personal. Ocurre tanto en la sociedad como en la Iglesia. Uno de los antídotos que propone Rahner y otros autores es la opinión pública, que permite la discusión y la pluralidad de posturas frente a distintos temas.

K. Rahner llama manipulación "sociológicamente institucionalizada" a la que se produce en las estructuras sociales. Esta pecaminosa manipulación institucional del ser humano es un aspecto de la condición concupiscente de la persona humana (1971: 29-30). También en la Iglesia, sostiene el teólogo alemán, se dan estructuras que favorecen la manipulación de sus miembros. Esta dimensión estructural de la manipulación es recogida por M. Vidal, citando el texto de K. Rahner, y la comprende, por un lado, como pecado estructural, y por otro, como culpabilidad colectiva (Vidal, 1980: 119). Así como la doctrina social de la Iglesia y el magisterio

\footnotetext{
8 En esa misma línea, Doris Reisinger subraya que el abuso de conciencia mata la libertad cristiana y, por lo tanto, hace imposible la misma vida de fe, que es un acto libre (Reisinger, 2021).
} 
del papa Juan Pablo II han aplicado la categoría de "estructuras de pecado" (Juan Pablo II, 1987) para juzgar instituciones o sistemas sociales que impiden o dificultan la vida digna de las personas, se podría análogamente aplicar esta categoría a estructuras eclesiales que son pecaminosas al propiciar ambientes que colaboran con la manipulación de los fieles.

En este sentido la Iglesia, como recuerda Lumen Gentium está siempre llamada a renovarse y purificarse para ser fiel a Jesucristo, su fundador y al Espíritu que la hace santa y la impulsa a la santidad, a la salvación también de sus propios pecados (Concilio Vaticano II, 1965a). Como asegura K. Rahner, la Iglesia debe ser el lugar de la libertad. Sin embargo, "quienes ostentan el poder, también dentro de la Iglesia, pueden sucumbir a la tentación de enmascarar la pecaminosidad de su relación con los otros" y así "legitimar un descomedido afán de poder" (1971: 62). Entre las propuestas para que una estructura social no sea manipuladora coinciden K. Rahner (1971), M. Vidal (1980), L. Oakley y J. Humphreys (2021) es que exista la posibilidad del desacuerdo y del disenso.

En el ámbito de las relaciones entre personas, las asimetrías de poder también pueden dar lugar a manipulación o abuso de conciencia. Por ejemplo, en el caso de la dirección/acompañamiento espiritual, que es legítima como un ministerio y servicio que media en el camino de santificación de los fieles, pero se enfrenta siempre al desafío de estar vigilantes ante situaciones donde puede darse la manipulación de quien es acompañado espiritualmente.

\subsection{Una reflexión teológico-moral sobre la manipulación de conciencia}

La reflexión teológico-moral sobre la conciencia ha tenido un nuevo impulso con el desarrollo que hizo el número 16 de Gaudium et spes (Majorano, 1994). En la década de los 70 se realizaron una serie de congresos de moralistas de distintos lugares de Europa sobre ética de la manipulación y manipulación de la ética (Vidal, 1980: 107-125).

En términos amplios "manipulación sugiere un conjunto de acciones mediante las cuales se manejan y se combinan diversos elementos para obtener un resultado especial, distinto del que podía esperarse de ellos abandonados a sí mismos" (Vidal, 1908: 109). Para comprender de modo más específico la manipulación de conciencia se puede mencionar a A. Luthe quien asegura que "los estímulos de la manipulación son percibidos de forma inconsciente; por medio de un arreglo hecho hábilmente permanecen ocultos a la conciencia" (1971: 173). Este autor afirma que "la víctima de las prácticas de manipulación cree falsamente que ha tomado una decisión racional" (1971: 98). 
Marciano Vidal, quien ha realizado un estudio sistemático sobre la manipulación de la conciencia moral, la define como "una acción que se adueña de las inevitables instancias acríticas de la conciencia moral para recrear otra conciencia ética que funciona según los intereses del manipulador" (1971: 112). Esta definición aporta luces sobre nuestra investigación, ya que, por una parte, señala que, a veces, la conciencia moral no toma decisiones de manera crítica, y por otra que puede estar bajo los intereses del manipulador. Para lograr esto el manipulador se "adueña" de las decisiones del manipulado mediante un proceso, esto no ocurre de un modo inmediato (Cruz, Hamilton \& Murillo, 2020). Además, si esto se da en el contexto del acompañamiento/dirección espiritual es el fiel quien ha confiado en esta persona que después de un tiempo termina manipulando sus decisiones vitales.

Por otra parte, M. Vidal, en su descripción de la manipulación de la conciencia moral, asegura que ésta "es una acción que tiene por ámbito de influencia el mundo ético de la persona, tanto en su momento objetivo (los valores) como subjetivo (la toma de conciencia moral)" (1971: 113). Ciertamente ambos aspectos son importantes, pero queremos insistir en la gravedad de influir, llegando incluso a suplantar, la toma de decisiones por parte de la víctima de manipulación. En esto insiste el moralista español: "La manipulación se introduce aquí por dos caminos: suplantando la responsabilidad personal mediante la proyección a un centro exterior de decisiones; $y$, falseando el proceso normal de la responsabilidad, mediante la distorsión de algunos de sus mecanismos" (1971: 114-115).

Un aspecto relevante en la manipulación y del abuso de conciencia es que no solo se da en un contexto creyente, sino que está directamente relacionado con su dimensión salvífica. La conciencia moral "está expuesta a la manipulación, la cual actuará utilizando los resortes eficaces de la "salvación controlada»" (Vidal, 1971: 116). Cuando manipula, el acompañante espiritual se aleja de su rol mediador y de representante de Dios, y manipula la conciencia de la víctima para que lo obedezca, apelando al vínculo de sus decisiones con la salvación personal.

\section{Perfilando El CONCEPTO DE ABUSO DE CONCIENCIA}

A partir de fines de los ochenta, comienza a denominarse, intuitivamente, abuso espiritual a formas de abuso psicológico en contextos religiosos, distintas del abuso sexual, que ya contaba con una terminología propia. Hay algo específico de ese contexto que tiende a distinguirlo del abuso psicológico o de autoridad a secas, aunque el abuso espiritual se da siempre en contextos asimétricos como el que media entre el dirigente de una comunidad religiosa y los miembros de esa comunidad. Lo que dis- 
tingue al abuso espiritual del abuso de poder no es, por lo tanto, esa asimetría relacional generada por la autoridad, sino el hecho de que se abusa de esa autoridad "en nombre de Dios" (Ward, 2011; Wehr, 2000) y que se afecta precisamente la relación de la persona con Dios, que es un elemento constitutivo de la conciencia (Concilio Vaticano II, 1965b: n. 16). Sin embargo, el abuso espiritual como forma de abuso de poder se asimila también a los abusos que se dan en el contexto de relaciones de cuidado, como el del médico y el paciente, el psicoterapeuta y la persona que es ayudada psicológicamente. Lisa Oakley, sin embargo, habla incluso de comunidades enteras que pueden producir abuso espiritual hacia quien ejerce la autoridad por medio de la presión de los pares (2021).

Quizás por ello, no ayuda mucho llamar simplemente abuso espiritual a los abusos que ocurren en un contexto que por definición es espiritual. Es necesario distinguir. Como bien señala Samuel Fernández, en estos contextos espirituales, particularmente en la Iglesia Católica, no existe sólo la autoridad formalmente constituida, sino también la autoridad carismática (2021: 561) ${ }^{9}$. Es por eso que los confines entre el abuso de poder y el abuso de conciencia no son claros y definidos. Por una parte, quien tiene autoridad formal, puede invadir la conciencia de la persona sujeta a ella por un vínculo de autoridad - lo que sería formalmente un abuso de poder, no un abuso de conciencia, puesto que la conciencia no está de suyo bajo la autoridad del que abusa-, por otra, la persona con autoridad carismática puede servirse de ese poder para subyugar la conciencia de una persona que voluntariamente le abre la puerta a ella. En este caso no habría formalmente un abuso de poder ${ }^{10}$, aunque el abusador se sirve de una forma de poder, que es su autoridad carismática. En ambos casos, sin embargo, hay un vicio en el ejercicio de la mediación de la autoridad divina, que toda mediación eclesiástica realiza. No es casualidad, que, al referirse a la mediación de la autoridad del superior religioso, se use la expresión "vices gerentes Dei", es decir, gobernar

\footnotetext{
9 S. Fernández usa el concepto de autoridad eclesiástica como un concepto amplio para cubrir las diferentes formas de ejercicio del poder en la Iglesia Católica. Si bien hay psicólogos que consideran el poder carismático como uno de los tipos de poder (Kessler, 2010), para el derecho canónico el poder descansa en el ejercicio del munus regendi por parte de los distintos oficios eclesiásticos. Cuando la ayuda espiritual no se da en el contexto de una relación de autoridad, nos parece que es más propia del munus sanctificandi como el caso de la dirección/acompañamiento espiritual o la misma confesión, que la misma Iglesia pide que se realice fuera de relaciones de autoridad.

10 Dado que la relación de cuidado propia del acompañamiento espiritual o de la confesión es canónicamente incompatible, la mayoría de las veces, con la relación de autoridad, el abusador no tiene potestad de régimen sobre el abusado.
} 
haciendo las veces de Dios (Juan Pablo II, 1983) ${ }^{11}$. Debe notarse, sin embargo, lo acotado de esta expresión al ámbito de la obediencia religiosa, que no es, en sentido propio, una obediencia de conciencia, sino sólo de voluntad. Es decir, se debe obedecer, en un ámbito restringido a aquello dispuesto por la normativa de la familia religiosa, no porque en conciencia se considere que es el mejor curso de acción, sino porque el superior es el intérprete auténtico de esa normativa. La extensión del concepto de obediencia religiosa fuera del ámbito de aquellos vinculados por voto a obedecer es ciertamente ilegítima, lo cual no quiere decir que no se aproveche la ignorancia de los fieles en esta materia para sobrepasar los límites de la autoridad. Sin embargo, dado que supone una forma inadecuada del ejercicio de la autoridad, esto sería un abuso de poder. La misma institución de la objeción de conciencia es un límite a la autoridad externa, de la cual se presupone que no puede interferir en el ámbito de la conciencia.

Hasta ahora, no existiendo el abuso de conciencia como un delito tipificado en el derecho canónico, se suele recurrir al c. 1389, 2 para sancionarlo ${ }^{12}$. Tal como reza el canon: "Quien abusa de la potestad eclesiástica o del cargo debe ser castigado de acuerdo con la gravedad del acto u omisión, sin excluir la privación del oficio, a no ser que ya exista una pena establecida por ley o precepto contra ese abuso" (Juan Pablo II, 1983). Estas dificultades de tipificación son invocadas por los acusados para defenderse, como dice Henzel: "Algunos de los que dicen ser acusados injustamente de esto [abuso espiritual] han respondido públicamente afirmando provocativamente: 'Nadie ha definido con objetividad lo que es el abuso espiritual, por lo tanto, nadie puede ser declarado culpable de algo tan ambiguo"' (1997).

Esto es cierto, si miramos la literatura, Ward llega a notar que no existe una definición consensuada de abuso espiritual (2011). Estudios más recientes siguen constatando que es difícil llegar a una definición compartida (Oakley \& Humphreys, 2021). Si este es el caso del concepto de abuso espiritual, con mayor razón podemos decir que definir abuso de

\footnotetext{
11 Ver Canon 601 del Código de Derecho Canónico, que evidentemente hace eco del decreto Perfectae caritatis, n. 14. La expresión tiene su origen, sin embargo, en el ámbito de la autoridad política, puesto que fue acuñada por Santo Tomás de Aquino en su obra De regno seu de regimine principum donde la usa cuatro veces para expresar que el gobernante gobierna participando de la autoridad divina. (Tomás de Aquino, 1948)

12 Es el caso del presbítero Jorge Óscar Portillo, sancionado por este motivo, además de abuso sexual, perpetrados en el Monasterio Cristo Orante en la Arquidiócesis de Mendoza, Argentina. Cf. Aclaración del Arzobispado de Mendoza sobre el caso de un sacerdote mendocino, 2021, texto disponible en https://aica.org/noticia-aclaracionsobre-la-condena-canonica-de-un-sacerdote-mendocino
} 
conciencia es difícil. Por otro lado, al tratar el tema de la intencionalidad del abuso, se suele distinguir la intencionalidad con respecto a las prácticas abusivas de la intencionalidad de provocar daño (Oakley \& Kinmond, 2013: 19) ${ }^{13}$. Estaríamos aquí en la frontera entre el dolo y la negligencia, sin embargo, nos parece que este elemento no afecta la definición de abuso de conciencia ni su distinción del abuso espiritual.

Una de las definiciones más sistemáticas de abuso espiritual propuestas hasta la fecha es la de Oakley y Humprheys:

El abuso espiritual es una forma de abuso emocional y psicológico. Se caracteriza por un patrón sistemático de comportamiento coercitivo y controlador en un contexto religioso. El abuso espiritual puede tener un impacto profundamente dañino en aquellos que lo experimentan.

Este abuso puede incluir: manipulación y aprovechamiento, rendición de cuentas forzada, censura de la toma de decisiones, exigencia de secreto y silencio, coerción para amoldarse, control mediante el uso de textos o enseñanzas sagradas, exigencia de obediencia al abusador, la suposición de que el abusador tiene una posición 'divina', aislamiento como medio de castigo, y superioridad y elitismo. (2021: 61)

Como se puede ver, se coloca el abuso espiritual en la categoría del abuso emocional y psicológico, que se distingue por la manipulación y el control sobre la víctima. Su carácter espiritual, sin embargo, se deriva del contexto en el que se da, el contexto religioso. Si bien en el abuso de conciencia lo central es la manipulación y el control, su elemento distintivo es que se hace "desde dentro" una vez que se ha logrado el acceso a la conciencia de la víctima, sea porque se la invade, sea porque la misma víctima concede este acceso, como es el caso de la relación de acompañamiento espiritual. Este acceso consentido hace que el abuso sea todavía más grave, puesto que la misma relación supone de entrada ese acceso y la víctima lo da por descontado, facilitando potencialmente el abuso. En ese sentido, el abuso de conciencia implica, además, una traición a la confianza de la víctima, que abre, de entrada, su conciencia a su victimario.

Todas estas dificultades teóricas no ayudan, desde luego, a la solución del problema de hacer cabalmente justicia en este ámbito de la tutela de los derechos de los fieles. A esto se añade que, en el abuso espiritual en general, y también en el abuso de conciencia, confluyen tres elementos que interactúan y cuya ponderación no es fácil de establecer (Wang,

13 "En muchos casos - incluidos los examinados por los autores- encontramos que, lejos de ser intencional, los que han caído en patrones de comportamiento espiritualmente abusivos, lo hicieron sin percatarse" (Oakley \& Humphreys, 2021: 149). 
2006: 52-59). En primer lugar, está el daño consciente o inconsciente realizado por el perpetrador o victimario. En segundo lugar, la vulnerabilidad de la víctima, no sólo por su colocación inferior en la asimetría de poder de la relación de cuidado, sino también, eventualmente, por características propias que pueden facilitar al victimario el acceso y el dominio de la propia conciencia. Naturalmente, puede tratarse de vulnerabilidades coyunturales o vulnerabilidades más permanentes, pero ambas facilitan que la víctima otorgue acceso al victimario a la propia conciencia. En tercer lugar, opera también un contexto comunitario disfuncional que facilita el abuso, al validar ciertas prácticas que impiden un adecuado control externo de las relaciones de cuidado ${ }^{14}$. Estas interacciones dificultan sobremanera la capacidad del juez eclesiástico para determinar la entidad del eventual delito de abuso de conciencia y ponderar el grado de culpabilidad del agresor.

Más allá de estas dificultades a la hora de comprender el fenómeno del abuso espiritual y una de sus categorías, como el abuso de conciencia, nos parece mejor utilizar abuso de conciencia en vez de abuso espiritual como término de referencia porque es la conciencia el "lugar" donde se verifica el abuso (Ripa, 2019) ${ }^{15}$; el abuso se produce, como ya se dijo, desde dentro, una vez que la víctima ha concedido acceso a este recinto interior. La palabra abuso espiritual no sólo nos parece demasiado genérica, sino que, sobre todo, no permite centrar la reflexión en el ámbito de la conciencia del fiel.

Nuestra propuesta apunta a una definición más restrictiva. Incorporando elementos de la terminología canónica, debemos decir que el abuso de conciencia se da de suyo en el fuero interno, esto es, al margen de una relación de autoridad formal entre víctima y victimario. La Iglesia es plenamente consciente de este peligro, por eso establece la así llamada distinción de fueros, es decir impide la simultaneidad de la potestad de gobierno y la potestad sacramental o espiritual ${ }^{16}$ hacia una misma persona. Sin duda es posible, conviene recordarlo una vez más, servirse de la autoridad para obligar a actuar en contra de la conciencia o para coaccionarla, pero, en este caso, se trata primariamente de una forma de abuso

14 Como señala L. Oakley, el rol del contexto comunitario es muy importante, sobre todo para que no se dé el paso de prácticas que puede ser dañinas al abuso en sentido estricto, gracias al control que ejerce la comunidad sobre las derivas patológicas de las relaciones de acompañamiento o de autoridad (Oakley, 2021).

15 Somos conscientes de que esta distinción neta no es universalmente aceptada. Creemos que es necesaria una definición lo más precisa y bien delimitada posible.

16 En la Iglesia, toda autoridad es espiritual, nos referimos a la autoridad sobre materias propias de la espiritualidad del fiel. 
de poder ${ }^{17}$, puesto que la autoridad está actuando más allá de sus atribuciones. Por definición la autoridad, no puede ejercerse en el ámbito de la conciencia, sino sólo en el fuero externo. En otras palabras, es propio del abuso de conciencia darse en una relación de cuidado, asimétrica, donde una persona abre voluntariamente su conciencia a otra con el fin de recibir ayuda y no en una relación de autoridad. Por ello, la Iglesia establece en el Código de Derecho Canónico que, en las comunidades religiosas o similares los superiores no deben inducir en modo alguno a los súbditos a confesarse con ellos o a manifestarles la conciencia fuera de la confesión (Juan Pablo II, 1983) ${ }^{18}$. En otras palabras, para que haya abuso de conciencia debe haber dos cosas: una relación asimétrica y la apertura de la conciencia de la parte débil a la parte fuerte como elemento propio de esta relación. Esto no quiere decir que no se pueda manipular la conciencia fuera de este contexto, pero sería mucho más difícil atribuir dolo o responsabilidad para efectos de una sanción. Por eso, no nos parece adecuado considerar que la formalidad propia del delito es el daño a la conciencia, esa sería una tipología basada en los bienes jurídicos protegidos, pero no en las relaciones que median en el delito (Fernández, 2021: 563). En todo caso, es verdad que mientras el abuso de poder coarta la libertad de acción, el abuso de conciencia coarta la libertad de juicio y la propia autopercepción ${ }^{19}$. Sin embargo, no es lo mismo invadir la conciencia que manipularla una vez que la víctima la abre al victimario. Ahí está la diferencia entre el abuso de poder y el abuso de conciencia en sentido propio.

Una vez que la relación abusiva se da en un contexto donde el abusador tiene acceso a la conciencia del abusado, la manipulación o coerción se da a lo largo de un espectro (Oakley, 2021), desde formas sutiles y leves de dominio hasta el total secuestro de la conciencia de la víctima. Por lo mismo, no es habitualmente posible diferenciar, desde el contenido, un consejo, con su evidente carga directiva, de la manipulación. La distinción está en la autoridad a la que apela el victimario para validar la

17 En este sentido, no parece adecuado, como hace Andrea Idalsoaga, calificar el abuso de conciencia como una forma de abuso de poder conforme al c. 1389, 1 (Idalsoaga, 2020). En esa misma línea Samuel Fernández (2021) entiende el abuso de conciencia como un abuso de poder que lesiona la conciencia. Es decir, su elemento constitutivo es el tipo de daño provocado en el ejercicio de la autoridad. Sin embargo, la discrecionalidad de la autoridad, que obviamente puede interferir con la libre determinación del fiel, no es un abuso de conciencia como tal sino sólo cuando afecta o pretende afectar el juicio de conciencia del fiel.

18 Ver Código de Derecho Canónico, c. 630, n. 4 y 5.

19 Este daño a la autopercepción y, por extensión, a la autoestima, está bastante bien descrito en los análisis de las dinámicas del abuso de conciencia (Oakley \& Humprheys, 2021: 108-109). 
orientación de la conducta de la víctima. Cuando el victimario se reviste indebidamente de la autoridad de Dios para validarla, tenemos el abuso de conciencia en sentido más propio. Es por eso que el abuso de conciencia implica la usurpación parcial o total de la autoridad de Dios. La fenomenología del abuso de conciencia nos da algunas expresiones típicas de esa usurpación, como validar la manipulación diciendo que "es la voluntad de Dios que...", principios como "el que obedece no se equivoca porque en última instancia obedece a Dios" o "como representante de Dios te digo que...". Puede haber formas camufladas, como cuando se utiliza la gracia de estado ${ }^{20}$ para reforzar la autoridad del consejo o bien se aplica a un caso particular una norma general como si fuera la única aplicación posible (Arterburn \& Felton, 1991) ${ }^{21}$. Las formas de pensar la apropiación divina son potencialmente infinitas, pero en todas sus formas, el abuso de conciencia implica apropiarse indebidamente de la voz de $\operatorname{Dios}^{22}$. Si queremos verlo desde la perspectiva de la mediación, en el abuso de conciencia, la mediación sustituye la autoridad que media, la de Dios, por lo que anula la libertad de la víctima. Es posible que esto suceda de un modo inconsciente o incluso negligente, cuando el acompañante carece de la formación adecuada por descuido propio o de quien avala su autoridad. Otras veces puede darse con plena advertencia de que la manipulación persigue el propio beneficio. No es infrecuente que se produzca una suerte de progresión en el espectro del abuso de conciencia mencionado arriba, desde formas más sutiles hasta formas abiertamente manipuladoras.

Dada esta usurpación de la autoridad divina, no es raro que el abuso de conciencia se dé sobre todo en las decisiones que expresan nuestra relación con Dios o con otras realidades espirituales. Sería una forma muy evidente de abuso utilizar el control de la conciencia para coaccionar comportamientos que no tienen nada que ver con el ámbito espiritual, como incidir sobre la alimentación, por ejemplo. Pero cuando se trata de influir en decisiones sobre el estado de vida o sobre la vida espiritual, el hecho de que afecten nuestra relación con Dios de modo más evidente puede hacer pasar desapercibida esta forma de abuso. La así llamada "inducción vocacional" es un buen ejemplo de esta sutil pero

\footnotetext{
20 Por gracia de estado se entiende la asistencia divina para el buen ejercicio de la autoridad o del acompañamiento espiritual.

21 El mismo concepto de fe tóxica (toxic faith), acuñado por los autores, debe ser abordado con la debida cautela, de modo de distinguir con rigor la religiosidad sana de la religiosidad patológica.

22 Utilizamos esta metáfora auditiva puesto que nos parece estar más en sintonía con la descripción de la conciencia que hace Gaudium et spes, 16.
} 
extremadamente grave forma de abuso de conciencia (Mertes, 2017) ${ }^{23}$. Un ejemplo de esto es lo que escribe James Hamilton sobre el abuso del expresbítero Fernando Karadima: "Nos decía cómo vestirnos, cómo relacionarnos con nuestros amigos e incluso nuestros padres biológicos. Qué carrera seguir, cuándo entrar al seminario, cuándo dejar la universidad o incluso con quién casarnos" (Cruz et al., 2020: 46).

Conviene recordar, sin embargo, que las decisiones moralmente buenas son genéricamente conformes a la voluntad de Dios, dado que nuestra realización personal es lo que Dios quiere para cada uno. El problema se da cuando se utiliza esta categoría para influir en decisiones individuales -que son propias de la conciencia de cada fiel-invocando la voluntad de Dios para un determinado curso de acción, que se presenta como el único conforme a esta voluntad. Es decir, se anula el discernimiento personal; además, en un contexto donde la víctima de entrada está buscando acoger la voluntad de Dios en su vida. Si el abusador aprovecha esta disposición para imponer su propio punto de vista, se sirve indebidamente de la fuerza de la imagen divina sobre la voluntad de la víctima para coaccionarla. No es infrecuente que las personas abusadas sean incapaces de delimitar exactamente con qué acto del victimario comenzó el abuso, porque se da en forma gradual.

Lisa Oakley y Justin Humprheys han intentado definir algunos elementos específicos que configuran el abuso espiritual y se pueden aplicar al abuso de conciencia. Estos elementos se refieren al contexto protestante, pero el paralelismo con instancias católicas es fácilmente trazable: (1) La noción de que la autoridad tiene origen divino; (2) El uso de la Sagrada Escritura y de la predicación (en ámbito católico podríamos añadir la confesión y el acompañamiento espiritual) para promover agendas propias y controlar el comportamiento; (3) El contexto espiritual favorece los discursos que justifican el abuso recurriendo precisamente a argumentos espirituales o teológicos; (4) La amenaza de consecuencias espirituales para los que no se pliegan a las directrices del abusador condenación eterna, degradación moral, es decir, no crecer en la humildad o ser soberbio si no se obedece-; (5) El impacto que tiene el abuso espiritual en las creencias básicas del propio credo (2021: 84-91). No es raro, por lo tanto, que las víctimas hablan de la dificultad para volver a creer (Oakley \& Kinmond, 2013: 73). Como sostiene José Andrés Murillo, el abuso espiritual y el abuso de conciencia comprometen la confianza, que es un presupuesto de la relación de autoridad en un contexto

23 K. Mertes describe muy detallada y sistemáticamente las formas que suele asumir en la praxis católica esta forma de abuso de conciencia que podríamos llamar "inducción vocacional". 
religioso o de una relación de cuidado (2020: 432). Y cuando el abuso se da en ese contexto el daño a la confianza en general, o a la confianza en Dios, que es el presupuesto para la fe, es absolutamente esperable.

\section{LA GRAVEDAD DEL ABUSO DE CONCIENCIA}

No todo pecado o conducta moralmente mala debe estar tipificada como delito en el derecho canónico. De hecho, son muy pocas las conductas que lo están. Nos parece obvio que el abuso de conciencia es un delito que afecta lo central que el derecho canónico quiere tutelar, que es el ámbito de nuestras relaciones con Dios. Más discutible puede ser el establecer su gravedad, por ello dedicamos esta sección de nuestro texto para argumentar el daño que esta forma de abuso puede provocar. Como argumenta Reisinger ${ }^{24}$, el abuso de conciencia puede llegar a impedir el acto de fe, al minar la libertad que lo sostiene (2021).

Podría decirse que el cuidado por el otro está en el centro de la moral evangélica. Por ello la Iglesia debe vigilar muy especialmente el recto ejercicio de estas relaciones de cuidado, particularmente aquellas que le son específicas como el cuidado espiritual por medio de los sacramentos y otras relaciones de cuidado no sacramentales, como la autoridad religiosa o el acompañamiento/dirección espiritual. La normativa canónica sobre el sigilo sacramental y sobre el sacramento de la confesión en general nos parece un claro ejemplo de esto, así como las regulaciones del munus regendi en general. Tratándose de relaciones asimétricas, donde está en juego el poder de lo sagrado nos parece que el acompañamiento/dirección espiritual requiere también una normativa más detallada en orden a prevenir abusos. En efecto, a diferencia de otras formas de cuidado espiritual, el objetivo principal de la dirección/acompañamiento es ayudar a discernir lo que Dios quiere de la persona acompañada desde su misma conciencia. Algo análogo se da en la confesión, donde el objeto propio es el discernimiento sobre lo que constituye pecado, pero precisamente por eso es un discernimiento más limitado y, en cierto modo más sencillo; es conocida la máxima de que los preceptos negativos son siempre más definidos que los positivos. Con todo, en todas estas relaciones de cuidado la asimetría es evidente. No se puede perder de vista, que se entra a esta relación de cuidado no a partir del simple reconocimiento de las competencias del que acompaña, sino porque se le atribuye alguna forma de mediación revestida de lo sagrado. Es por ello que, por analogía, el abuso de conciencia es una forma de sacrilegio (Von Kette-

24 Doris Reisinger y Doris Wagner son la misma persona, sin embargo, cambió su apellido por el matrimonio contraído. 
ler, 2020), porque se entra indebidamente en el sagrario del ser humano (Concilio Vaticano II, 1965b: n. 16).

El abuso de conciencia es también grave porque el ingreso a este sagrario requiere de suyo especial prudencia. De ahí que la Iglesia enseñe que este servicio requiere de competencias específicas que deben ser especialmente reconocidas (Juan Pablo II, 1992) ${ }^{25}$. Por eso la cura animarum, por medio del oficio de párroco o del acompañante espiritual constituye un oficio que debe ser reconocido por la autoridad eclesiástica (Juan Pablo II, 1983) ${ }^{26}$. El abuso de conciencia por parte de estos bautizados especialmente constituidos para estas relaciones de cuidado- afecta la credibilidad de las mediaciones eclesiales, además de dañar la integridad psicológica -a veces física- de las víctimas. Por ello no extrañan afirmaciones como la de Doris Wagner: "Para mí, personalmente, este abuso espiritual y las consecuencias que tiene en mi vida son mucho peores que la violencia sexual que he experimentado" (2019a). Entre las consecuencias del abuso espiritual suele darse que la experiencia espiritual de la víctima, de suyo buena, queda contaminada, a veces irremediablemente, con la experiencia abusiva (Wehr, 2000: 46).

Mirado desde la óptica del victimario, el abuso espiritual es una clara deformación de su rol propio, que es la salvación de las personas a través de su cuidado. Revestirse indebidamente de la autoridad divina para utilizar para fines ilegítimos es una forma de suplantación. El carácter absoluto de la autoridad suplantada, la divina, hace que sea una forma particularmente grave de violación del oficio concedido. No es este el lugar para desarrollar una teología de la mediación, pero es claro que usurpar el lugar de Dios es una evidente transgresión de los límites que tiene toda mediación humana de la autoridad divina.

Mientras todas estas consideraciones tienen que ver con la naturaleza de la relación de cuidado, donde se da el abuso de conciencia, no es difícil entender que hay ciertas consecuencias del abuso que pueden ser particularmente graves y que esta gravedad puede ser fácilmente intuida, al punto de no justificar la ignorancia en aquel que las provoca. Se trata del hecho de que, con mucha frecuencia, el abuso de conciencia afecta decisiones que son trascendentales para la víctima, como su estado de vida,

25 Ver Catecismo de la Iglesia Católica, n. 2690.

26 Si bien en el caso de los párrocos estas cualidades son reconocidas en forma amplia (c. 521), cuando se trata de comunidades más formalmente constituidas deben ser validadas por la autoridad competente, como los directores espirituales de seminaristas o casas religiosas. Ver c. 239, 2; 630. Es verdad que el acompañamiento espiritual no es exclusivo de las personas que revisten ese oficio, pero los demás acompañantes asumen al menos implícitamente un rol de mediación que debe ser tutelado. 
sus relaciones más esenciales como aquellas familiares o de amistad o decisiones que tienen impacto en el largo plazo, como decisiones laborales o de estudios superiores. Es evidente el grave perjuicio que se deriva del fracaso matrimonial o del abandono de los deberes asociados al orden sagrado o de la vida religiosa. Estas decisiones vitales son demasiado relevantes en la vida de los fieles para que se pueda interferir abusivamente en ellas con dolo o sólo con negligencia. No es inusual que, al abandonar grupos de alto control, muchos consagrados y presbíteros cuestionen su vocación ${ }^{27}$. Ser víctimas de abuso espiritual no implica necesariamente que la decisión vocacional esté contaminada por elementos de coerción sutiles, pero potentes, pero sí es probable que lo sea. Debe ser un elemento para tomar en cuenta toda vez que se examinan solicitudes de dispensa de las responsabilidades derivadas del orden sacerdotal o de indultos de salida de congregaciones religiosas. No puede excluirse a priori que el abuso espiritual determine la nulidad de los votos religiosos o de la ordenación sacerdotal, aunque somos conscientes de la escasa jurisprudencia que existe en este sentido.

\section{CONCLUSIÓN}

Como hemos mostrado, el fenómeno de la manipulación de conciencia no es algo nuevo. El uso del término abuso de conciencia, por parte del Papa Francisco, sin duda ha ayudado a ponderar más cuidadosamente su gravedad. Con las reflexiones precedentes, queremos ofrecer una contribución razonada para avanzar hacia una necesaria tipificación penal canónica de esta forma de abuso, en línea con lo señalado por la delegada para la Justicia y la Paz de la arquidiócesis de Santiago de Chile (Idalsoaga, 2020).

Tratando de delimitar los elementos del tipo penal, debe quedar claro que el sujeto activo no es sólo el presbítero, puesto que el abuso de conciencia puede darse fuera de la confesión y, por tanto, por un diácono o un laico o consagrado que no ha recibido el sacramento del orden. Por otro lado, tampoco puede restringirse el delito sólo a aquellos que han recibido un oficio eclesiástico que valida sus relaciones de acompañamiento espiritual, sino a cualquier acompañante espiritual, haya o no sido canónicamente habilitado para este oficio.

El sujeto pasivo es todo fiel que entra en una relación de cuidado que implica de suyo la apertura de la conciencia, como es el acompaña-

27 Las referencias más conocidas para los autores son el caso de los Legionarios de Cristo y de la Unión Sacerdotal congregada en torno al expresbítero Fernando Karadima. 
miento espiritual (o la confesión). El tipo penal puede definirse como la coacción indebida de la conciencia del sujeto pasivo, en cuanto se reviste la coacción de atributos que no le competen, particularmente del uso indebido de la autoridad divina.

La distinción del abuso de conciencia del abuso de poder permite, además, considerar delitos a comportamientos que no caen bajo ese tipo penal, distinto del abuso de poder. Por otro lado, consideramos que un tipo penal específico permite percibir con más claridad la gravedad del abuso de conciencia y sus consecuencias en las víctimas, que exigen justicia y reparación.

Finalmente, compartimos con Lisa Oakley (2021) la idea de que el abuso espiritual -y análogamente el abuso de conciencia- se da como un espectro de conductas puntuales que van avanzando en frecuencia y grado de coacción. Tratándose de distinciones cuantitativas, no es fácil establecer la demarcación de dónde comienza el delito, pero al menos nos parece que la persistencia de las conductas de coacción al menos por varios meses (tanto del sujeto activo o en la relación de él con el sujeto pasivo), debería ser un requisito necesario para que esta forma de abuso adquiera las características de un delito. Es decir, un victimario que ha abusado en el tiempo de muchas personas o, al menos, de una persona durante suficiente tiempo.

Comprendemos que estos límites que proponemos no son del todo claros. Puede ser más fácil, para poder facilitar la determinación jurídica del tipo penal, indicar algunos campos donde esta interferencia es de especial gravedad. Por ejemplo, en el discernimiento vocacional, en las relaciones familiares y otras realidades afines, donde el control por parte del victimario alcanza comportamientos que tienen gran impacto en la vida de la víctima. Por otro lado, son conductas relativamente fáciles de acreditar, a partir de la constatación de los comportamientos inducidos.

$\mathrm{Al}$ igual que otras formas de abuso, reconocer la existencia del abuso de conciencia es ya un paso importante y necesario (Oakley \& Kinmond, 2013: 74) para proteger a las víctimas y comenzar procesos de reparación, de sanación y de creación de ambientes eclesiales más sanos, que resulten protectores para todos los fieles.

\section{REFERENCIAS}

Arterburn, S. \& Felton, J. (1991). Toxic faith: Understanding and overcoming religious addiction. Nashville: Oliver-Nelson.

Booth, L. (1991). When God becomes a drug. Los Ángeles: Jeremy Tarcher.

Borgoño, C. \& Hodge, C. (2020). El abuso de conciencia. Primera aproximación a un problema emergente. Revista Católica, (1207), 69-73. 
Chávez, P. (2021). La conciencia moral. Santuario de la persona, patrimonio de la humanidad. En L. Valera \& M. A. Carrasco (ed.), Manual de Ética Aplicada: De la teoría a la práctica (pp. 119-130). Santiago de Chile: Ediciones UC.

Concilio Vaticano II. (1965a). Lumen Gentium. Disponible en https://www.vatican.va/archive/hist_councils/ii_vatican_council/docum ents/vat-ii_const_19641121_lumen-gentium_sp.html.

Concilio Vaticano II. (1965b). Gaudium et spes. Disponible en https://www.vatican.va/archive/hist_councils/ii_vatican_council/docum ents/vat-ii_const_19651207_gaudium-et-spes_sp.html.

Concilio Vaticano II. (1965c). Dignitatis humanae. Disponible en https://www.vatican.va/archive/hist_councils/ii_vatican_council/docum ents/vat-ii_decl_19651207_dignitatis-humanae_sp.html.

Cruz, J.C., Hamilton, J. \& Murillo, J.A. (2020). Abuso y poder. Nuestra lucha contra la Iglesia católica. Santiago de Chile: Debate.

Damasio, R. (2010). Y el cerebro creó al hombre: ¿cómo pudo el cerebro generar emociones, sentimientos, ideas y el yo? Barcelona: Destino.

Enroth, R. (1993). Churches that abuse. Grand Rapids: Zondervan.

Fernández, S. (2021). Towards a definition of abuse of conscience in the catholic setting. Gregorianium, 102(3), 557-574.

Francisco. (2013). Discurso a los participantes de la Asamblea Plenaria del Pontificio Consejo para las Comunicaciones Sociales del 21 de septiembre de 2013.

Disponible

en https://press.vatican.va/content/salastampa/it/bollettino/pubblico/2013 /09/21/0593/01321.html

Francisco. (2018). Carta del Santo Padre Francisco al Pueblo de Dios que peregrina en Chile.

Disponible

en http://www.vatican.va/content/francesco/es/letters/2018/documents/p apa-francesco_20180820_lettera-popolo-didio.html

Francisco. (2021). Constitución Apostólioca Pascite gregem Dei con la que se reforma el libro VI del Código de Derecho Canónico. Disponible en https://www.vatican.va/content/francesco/es/apost_constitutions/docu ments/papa-francesco_costituzione-ap_20210523_pascite-gregem-dei.html

Freiin Von Ketteler, E. (2020). El abuso de conciencia como acto sacrílego y las consecuencias teológico-pastorales derivadas de esta identificación. Promanuscripto de Tesina para optar al certificado académico en Teología Pastoral. Santiago de Chile.

Gubi, P. \& Jacobs, R. (2009). Exploring the impact on counsellors of working with spiritually abused clients. Mental Health, Religion and Culture, 12(2), 191204.

Henzel, R. (1997). The Bible and spiritual abuse. Disponible en www.geocities.com/Athens/Forum/9575/ biblespirab.html

Higuera Udías, G. (1985). Ética y manipulación humana. Miscelánea Comillas, 43(83), 419-436. 
Idalsoaga, A. (2020). Abuso de poder: aprendizaje y desafíos. La Revista Católica, (1206), 76-80.

Johnson, D. \& Van Vonderen, J. (1991). The subtle power of spiritual abuse. Minneapolis: Bethany House.

Juan Pablo II (1992). Catecismo de la Iglesia Católica. Ciudad del Vaticano: Libreria Editrice Vaticana.

Juan Pablo II. (1993). Código de Derecho Canónico. Ciudad del Vaticano: Libreria Editrice Vaticana.

Juan Pablo II (1987). Sollicitudo rei socialis. Ciudad del Vaticano: Libreria Editrice Vaticana.

Kessler, V. (2010). Leadership and Power. Koers. Bulletin for Christian Scholarship, 75(3), 527-550.

Luthe, A. (1971). ¿Qué se entiende por manipulación? Concilium. Revista Internacional de Teología, (65), 169-186.

Majorano, S. (1994). La Coscienza. Per una lettura cristiana. Milano: San Paolo.

Melina, L., Noriega, J. \& Pérez-Soba, J. J. (2007). Caminar a la luz del amor. Los fundamentos de la moral cristiana. Madrid: Ed. Palabra.

Mertes, K. (2017). Geistlicher Machtmissbrauch. Geist und Leben, 90, 249-259.

Murillo, J. A. (2020). Abuso sexual, de conciencia y de poder. Una nueva definición. Estudios Eclesiásticos, 95(2), 415-440.

Oakley, L. (2021). Abuso de conciencia, perspectivas ecuménicas. Webinar realizado en junio de 2021, disponible en https://teologia.uc.cl/en/congresos-y-seminarios-ver/1887-webinarabuso-espiritual-y-abuso-de-conciencia-perspectivas-ecumenicas.

Oakley, L \& Humphreys, J. (2021). Escapando del laberinto del abuso espiritual. Santiago de Chile: Ediciones UC.

Oakley, L. \& Kinmond, K. (2013). Breaking the silence on spiritual abuse. New York: Palgrave MacMillan.

Oakley, L., Kinmond, K. \& Humphreys, J. (2018). Spiritual abuse in Christian Faith Settings. Journal of Adult Protection, 20(3/4), 144-154.

Pacheco Romero, J. (2019). Abuso o manipulación de conciencia. Revista CLAR, 57(2), 18-23.

Rahner, K. (1971). Libertad y manipulación en la sociedad y en la Iglesia. Pamplona: Ed. DINOR.

Reisinger, D. (2021). Abuso espiritual y vida religiosa. Promanuscripto de la conferencia dictada en el Webinar sobre abuso espiritual organizado por la Unión de las Conferencias Europeas de Superiores Mayores, 28 de abril de 2021.

Ripa, A. (2019). Considerazioni a propósito dell'abuso spirituale, o di coscienza. Manuscrito sin publicar que recoge el contenido de una conferencia dirigida a los Rectores de los Colegios y Residencias Sacerdotales romanas impartida el 21 de noviembre de 2019.

Rodríguez Luño, A. (2007). Aclaraciones sobre el concepto de fuero interno y fuero externo.

Disponible

en 
https://www.eticaepolitica.net/eticafondamentale/arl_fuero $\% 28$ es $\% 29 . p d$ $\mathrm{f}$

Tomás de Aquino (1948). De regimine principum ad regem Cypri. Turín: Marietti.

Vidal, M. (1980). Discernimiento ético. Hacia una estimativa moral cristiana. Madrid: Ed. Cristiandad.

Wagner, D. (2019). Spiritueller Missbrauch in der Katolischen Kirche. Friburgo: Herder.

Wagner, D. (2019a). Entrevista concedida a K. Dietrich en la radio MDR. https:/ / www.mdr.de/religion/spiritueller-missbrauch-in-derkirche100.html

Wang, C. (2006). The use and misuse of pastoral power. A theological reflection on the issue of spiritual abuse. Promanuscripto de tesis doctoral. Toronto, 2006.

Ward, D. (2011). The Lived Experience of Spiritual Abuse. Mental Health, Religion \& Culture, 14(9), 899-915.

Wehr, D. (2000). Spiritual abuse: when good people do bad things. En P. Young-Eisendrath \& M. Miller (ed.), The Psychology of Mature Spirituality. Integrity, Wisdom, Transcendence (pp. 37-48). Londres: Routledge. 